Article

\title{
Experimental Study of Entrainment and Mixing of Renewable Active Particles in Fluidized Beds
}

\author{
Botond Szucs $1, * \mathbb{D}$, Mohamed Sobhi Alagha ${ }^{1,2} \mathbb{D}$ and Pal Szentannai ${ }^{1,3} \mathbb{D}$ \\ 1 Department of Energy Engineering, Faculty of Mechanical Engineering, Budapest University of Technology \\ and Economics (BME), 1111 Budapest, Hungary \\ 2 Department of Mechanical Engineering, Faculty of Engineering, Kafrelsheikh University, \\ 61519 Kafrelsheikh, Egypt; alagha@energia.bme.hu \\ 3 Fuel and Reactor Materials Department, Hungarian Academy of Sciences Centre for Energy Research, \\ 1121 Budapest, Hungary; szentannai@energia.bme.hu \\ * Correspondence: szucsbotond@energia.bme.hu
}

Received: 8 May 2020; Accepted: 16 June 2020; Published: 22 June 2020

\begin{abstract}
Fluidized bed combustors were initially designed and built basically for the utilization of fossil fuels, mostly coal. The actual worldwide trend of transitioning from fossil fuels to renewables requires sufficient knowledge on the fluid mechanics of these new particle types because of the significant differences in their shapes, sizes, densities, and homogeneities. This article presents experimental results on the particle entrainment and mixing of some industrially relevant fuels such as solid refused fuel/refuse derived fuel (SRF/RDF), bark, sunflower shell, and wheat shell. The measurements were performed on a lab-scale fluidized bed experimental facility. The results show that sunflower shell is entrained in the highest degree; however, at very low velocity, the entrainment of wheat shell is the most intensive. The entrainment behaviors of the investigated SRF and bark samples are similar. On the other hand, the mixing results showed that the SRF has relatively high mass fractions in the bottom and centeral regions of the fluidized bed at low superficial velocities, while at elevated velocities, the entire mass of this fuel is shifted upwards. Interestingly, just the opposite tendency can be observed in cases of all other investigated biomass fuels. Finally, the nonspherical renewable active particles have markedly higher concentrations in the bottom region of the bed compared to spherical ones.
\end{abstract}

Keywords: fluidized bed; SRF/RDF; bark; sunflower shell; wheat shell; entrainment; mixing; renewable; fuel; active particle

\section{Introduction}

Nowadays, the waste-to-energy principle becomes popular due to the energy problem and the global awareness of the dangers of greenhouse emissions. Fluidized bed conversion is a clean energy technology that utilizes a wide variety of solid hydrocarbonaceous fuels such as coal, biomass, and municipal solid waste. Fluidized beds have excellent mixing and heat transfer characteristics [1]. However, their operating parameters were originally optimized for coal.

The current trend is to partially or fully replace fossil fuels by renewable fuels such as solid refused fuel (SRF) and biomass. The energy content of these renewable fuels is competitive to lignite as shown in Table 1.

Table 1. Comparison of the calorific values of renewable fuels and lignite.

\begin{tabular}{cccccc}
\hline & SRF & Bark & Sunflower shell & Wheat straw & Lignite \\
\hline Calorific value, MJ $/ \mathrm{kg}$ & $13.6-14.9[2]$ & $16.0-17.5[3]$ & $17.4-18.8[4]$ & $18.5-19.8[5]$ & $23.6-24.6[6]$ \\
\hline
\end{tabular}


The challenge is that these renewable fuels have different physical, chemical, and geometrical properties. Thus, to reach the efficient processing of these heterogeneous fuels in fluidized beds, there is a need to understand their fluid-dynamics and mixing characteristics.

There are plenty of literature studies that investigated the thermochemical conversion of renewable fuels [7-15]. However, only a few of them addressed their fluid dynamical context. A recent paper [16] studied the vertical arrangement of SRF in binary-mixture bubbling fluidized beds. The authors reported the PI-segregation phenomena, that is, a simultaneous separation from the bed body regime towards the top and bottom regimes at low velocities. Zhou et al. [17] and Yang et al. [18] investigated the effect of particle size distribution of the bed material on the gas yield of biomass gasification. They concluded that wider particle size distribution (PSD) enhances the gas yield due to the higher carbon conversion efficiency. Kraft et al. [19] studied the effect of the hydrodynamic parameters on char mixing in a dual fluidized bed biomass gasification plant. They used bronze and polyethylene particles as representatives of the bed and char particles, respectively, in their cold flow model. They measured the char concentration in the recirculation stream by taking samples from the return leg. They reported that the char concentration in the recirculation stream decreases with increasing the bed height. And, rising the fluidization rate increases the char concentration in the recirculation stream. Köhler et al. [20] used a density-similar magnetic particle tracer to simulate the mixing and segregation of different active particles in a cold-flow bubbling fluidized bed. They identified three fuel segregation regimes based on the fluidization velocity and the density of the tracer particle. Earlier, Win et al. [21] investigated the transport velocity of coarse particles in a multi-solid fluidized bed system. They reported that the transport velocity of coarse particles decreases with increasing the solids circulation rate.

Concluding over the literature survey, we can say that the study of the fluid dynamic characteristics of coarse active particles was not covered with sufficient details. For example, the majority of the literature measurements were performed on representative particles (spherical tracer or spherical beads). However, the real heterogeneous properties of the active particles are more complex and are expected to have some differences in behavior compared to the representative spherical particles.

In the present study, entrainment and mixing measurements are performed on SRF, bark, sunflower shell, and wheat shell. The results of these nonspherical and heterogenous are presented and analyzed. The entrainment results of the investigated fuel particles were plotted on the Haider-Levelspiel chart to obtain the representative sphericity values. Also, the vertical arrangements of these fuels in binary-mixture fluidized beds are discussed. Finally, the axial concentration profiles of these nonspherical active particles are compared to the probability function of the presence of a spherical tracer measured by others.

\section{Materials and Methods}

\subsection{Biomass Fuels and Bed Material}

The renewable active particles examined in the present study are Solid Recovered Fuel (SRF), bark, sunflower shell, and wheat shell (see Figure 1). The samples were taken from a Hungarian waste treatment plant. The characteristics of the active particles used in the present study are shown in Tables 2 and 3. The examined SRF corresponds to the European standard EN 15359. This standard classifies the SRF based on the net calorific value (NCV), sulfur (S), and chlorine (Cl) data. According to this standard, the examined SRF is classified as 4,2,2. The bark is classified as a non-hazardous waste from the wood processing industry according to the European waste code (EWC code: 030101). Because it is available in a high amount, it can be utilized as renewable biomass fuel in fluidized bed power plants. Sunflower and wheat shells are agricultural wastes, and their availability is seasonal. Because of their high heating values, it is economical to store and transport them. In general, these 
biomass fuels are secondary or waste biomasses. Thus, the utilization of these fuels does not affect the agricultural food cultivation.

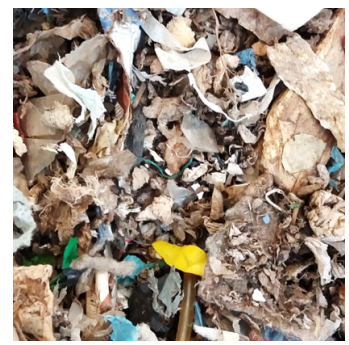

(a) SRF

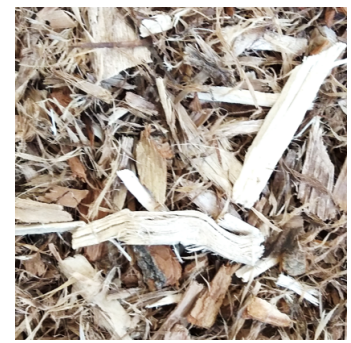

(b) Bark

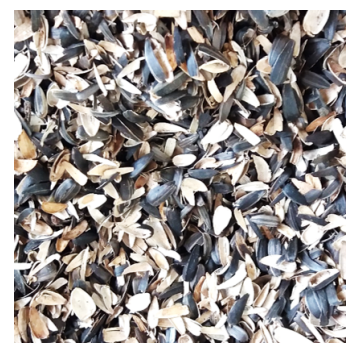

(c) Sunflower shell

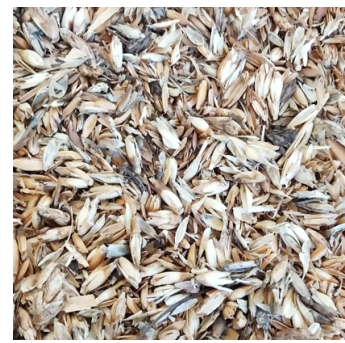

(d) Wheat shell

Figure 1. Photographic view of the active particles used in the present study. (The original horizontal length of each photo is $7 \mathrm{~cm}$ ).

Table 2. Chemical characteristics of the active particles used in the present experiments.

\begin{tabular}{|c|c|c|c|c|c|c|c|c|c|c|}
\hline & $\begin{array}{c}\text { Moisture } \\
\text { (wt.\%) }\end{array}$ & $\begin{array}{c}\text { Ash } \\
\text { (wt.\%) }\end{array}$ & $\begin{array}{l}\text { Volatile } \\
\text { (wt.\%) }\end{array}$ & $\begin{array}{c}\text { S } \\
\text { (wt.\%) }\end{array}$ & $\begin{array}{c}\mathrm{C} \\
\text { (wt.\%) }\end{array}$ & $\begin{array}{c}\mathrm{H} \\
\text { (wt.\%) }\end{array}$ & $\begin{array}{l}\text { HHV } \\
(\mathrm{MJ} / \mathrm{kg})\end{array}$ & $\begin{array}{c}\text { LHV } \\
(\mathrm{MJ} / \mathrm{kg})\end{array}$ & $\begin{array}{c}\mathrm{Cl} \\
\text { (wt.\%) }\end{array}$ & $\begin{array}{c}\mathrm{N} \\
\text { (wt.\%) }\end{array}$ \\
\hline \multirow{6}{*}{ 离 } & \multicolumn{10}{|c|}{ Analysis data in wet (raw) state } \\
\hline & 13.20 & 34.90 & - & 0.160 & - & - & 14.40 & 12.60 & 0.510 & - \\
\hline & - & - & - & - & - & - & - & - & - & - \\
\hline & \multicolumn{10}{|c|}{ Analysis data in dry state } \\
\hline & 3.37 & 74.7 & - & 0.28 & - & - & 24.20 & 22.20 & 0.870 & - \\
\hline & - & - & - & - & - & - & - & - & - & - \\
\hline \multirow{6}{*}{ 䒕 } & \multicolumn{10}{|c|}{ Analysis data in wet (raw) state } \\
\hline & 15.83 & 4.07 & 61.5 & 0.057 & 41.81 & 6.89 & 15.94 & 14.05 & 0.076 & 0.384 \\
\hline & EN 14774 & EN 14775 & EN 15148 & - & - & - & ISO 1928 & ISO 1928 & ISO 587 & - \\
\hline & \multicolumn{10}{|c|}{ Analysis data in dry state } \\
\hline & - & 4.84 & 73.1 & 0.067 & 49.68 & 8.18 & 18.94 & 17.15 & 0.090 & 0.456 \\
\hline & - & EN 14775 & EN 15148 & - & - & - & ISO 1928 & ISO 1928 & ISO 587 & - \\
\hline \multirow{6}{*}{ 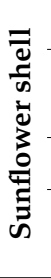 } & \multicolumn{10}{|c|}{ Analysis data in wet (raw) state } \\
\hline & 8.47 & 2.28 & 69.1 & 0.180 & 46.81 & 7.87 & 19.16 & 17.24 & 0.058 & 0.884 \\
\hline & EN 14774 & EN 14775 & EN 15148 & - & - & - & ISO 1928 & ISO 1928 & ISO 587 & - \\
\hline & \multicolumn{10}{|c|}{ Analysis data in dry state } \\
\hline & - & 2.49 & 75.5 & 0.190 & 51.14 & 8.60 & 20.94 & 19.06 & 0.063 & 0.966 \\
\hline & - & EN 14775 & EN 15148 & - & - & - & ISO 1928 & ISO 1928 & ISO 587 & - \\
\hline \multirow{6}{*}{ 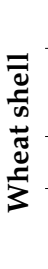 } & \multicolumn{10}{|c|}{ Analysis data in wet (raw) state } \\
\hline & 12.97 & 9.90 & 64.4 & 0.347 & 40.95 & 8.09 & 17.01 & 14.93 & 0.085 & 1.808 \\
\hline & EN 14774 & EN 14775 & EN 15148 & - & - & - & ISO 1928 & ISO 1928 & ISO 587 & - \\
\hline & \multicolumn{10}{|c|}{ Analysis data in dry state } \\
\hline & - & 11.38 & 74.0 & 0.399 & 47.05 & 9.29 & 19.54 & 17.52 & 0.098 & 2.077 \\
\hline & - & EN 14775 & EN 15148 & - & - & - & ISO 1928 & ISO 1928 & ISO 587 & - \\
\hline
\end{tabular}

Most characteristic data of the investigated fuels were obtained by generally known or even standard methods, as stated in Table 2. Some further data in Table 3 were measured by specific procedures as described hereafter. The density measurements were carried out by using two different methods, (i) the gas-pycnometer method and the (ii) bulk volume method. These two methods are commonly used for density measurements of irregular granular materials. In the gas-pycnometer method, the sample is placed in a calibrated volume, and the gas (Helium) flow is opened to fill the space around the particles in the chamber. The gas fills all the cavities within the sample, and the measured density is called the skeleton density. In the other method, instead of the gas, we immerse 
the irregular particulate material in a fine powder (fine sand) to fill the relatively large voidage in the sample (among the irregular particles). The calibrated tube containing the powder is mechanically vibrated till the fine powder fills all the gaps. Then, the irregular granular sample volume can be determined by subtracting the fine powder volume. The density measured by this method is called the apparent density, i.e., the density of the granular material near the maximum packing limit.

The bed material used throughout the investigations of the present study is a commercially available sand. Its mean diameter is $0.81 \mathrm{~mm}$, and many further characteristic data of this material were presented elsewhere [16].

Table 3. Physical and geometric characteristics of the active particles used in the present experiments.

\begin{tabular}{lllll}
\hline & SRF & Bark & Sunflower shell & Wheat shell \\
\hline Skeleton density, $\mathrm{kg} / \mathrm{m}^{3}$ & 1400 & 1253 & 1876 & 1446 \\
\hline Apparent density, $\mathrm{kg} / \mathrm{m}^{3}$ & 325 & 600 & 338 & 415 \\
\hline Particle shape, - & $\begin{array}{l}\text { diverse irregular } \\
\text { shapes }\end{array}$ & $\begin{array}{l}\text { stringy and } \\
\text { chips-like }\end{array}$ & $\begin{array}{l}\text { half-ellipsoidal } \\
\text { shell-like }\end{array}$ & $\begin{array}{l}\text { ellipsoidal } \\
\text { shell-like }\end{array}$ \\
\hline Particle structure, - & $\begin{array}{l}\text { ductile (big-sizes) } \\
\text { hard (small-sizes) }\end{array}$ & $\begin{array}{l}\text { ductile (stringy), } \\
\text { hard (chips) }\end{array}$ & hard & elastic \\
\hline Source, - & $\begin{array}{l}\text { waste (textile, } \\
\text { plastic, etc) }\end{array}$ & wood industry & sunflower seeds & wheat crop \\
\hline
\end{tabular}

\subsection{Particle Size Analysis}

The particle size distribution (PSD) analysis was performed by using a MATLAB code that is based on a sieveless segmentation technique [22-24]. The imaging setup is shown in Figure 2.

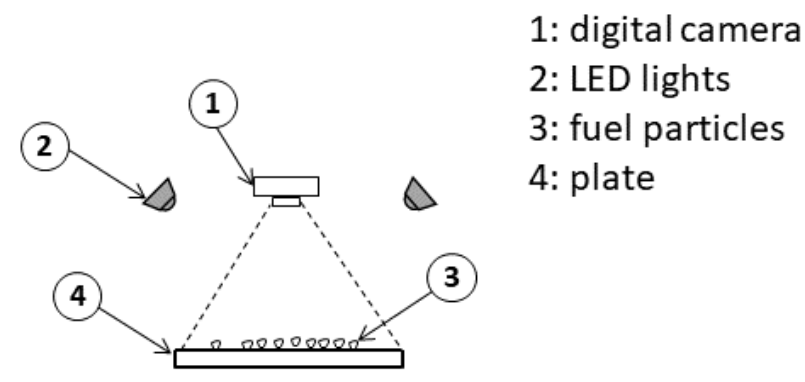

Figure 2. The setup of the particle size analysis.

The MATLAB Image Processing Toolbox contains built-in functions that calculate the equivalent diameter of the nonspherical shapes in the image. The toolbox gives the values in pixels, and a user-defined function was implemented to get the equivalent particle diameter $d_{\mathrm{i}} \mathrm{in} \mathrm{mm}$, to handle the specific properties of the photos, and to do the further calculations.

\subsection{Particle Entrainment Measurements}

Figure 3 shows the schematic view of the lab-scale test rig used in the particle entrainment experiments. The test rig consists of a riser from plexiglass and has an internal diameter of $192 \mathrm{~mm}$. Here, only the SRF, bark, sunflower shell, and wheat shell particles were investigated (used and put into the facility), which are otherwise the active particles. The air volume flow was measured with an inlet orifice connected to a manometer. A radial blower was used to produce the desired airflow through the air distributor, which consists of 1160 nozzles of $1 \mathrm{~mm}$ diameter each. At the outlet of the riser, a separator is used to detach the entrained particles from the airflow. 


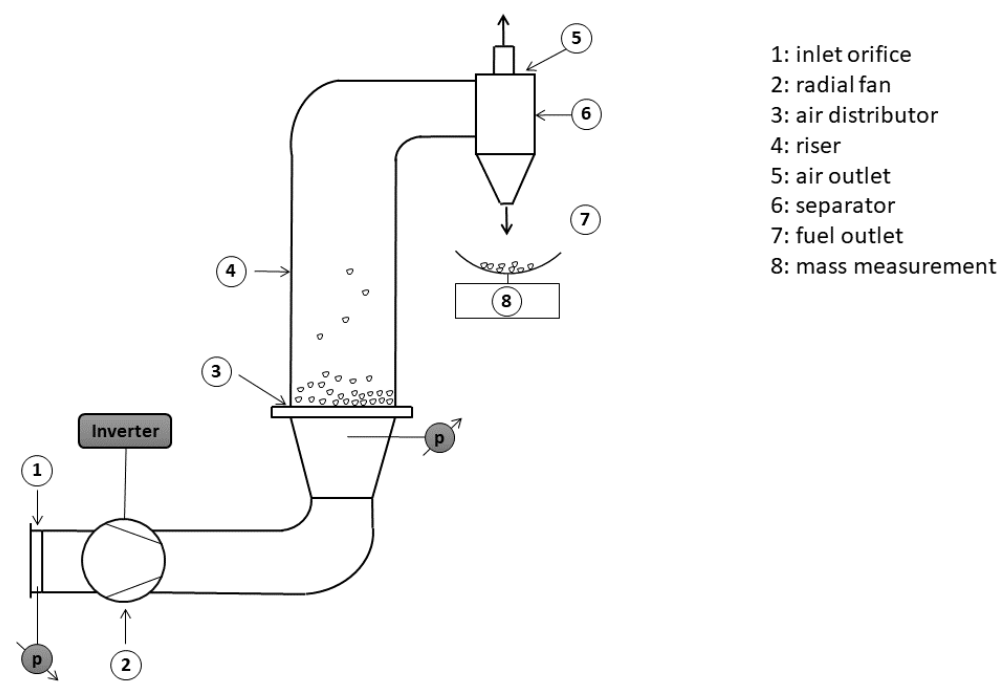

Figure 3. Schematic of the experimental setup of the active particle entrainment tests.

The measurement method consists of the following steps:

- Filling the riser with about $50 \mathrm{~g}$ of the investigated particles.

- Increasing the fluidization air velocity.

- Measuring the entrained fuel amount in the filter at five fluidization velocities within the range of $1-3 \mathrm{~m} / \mathrm{s}$.

- Plotting the entrainment curve between the normalized entrained mass and the fluidization velocity.

\subsection{Particle Mixing Measurements}

Mixing of the fuel particles in binary-mixture fluidized beds was measured by the commonly used bed-frozen method [25-28] (see Figure 4). The active particles were well mixed with the bed material prior to all measurements.

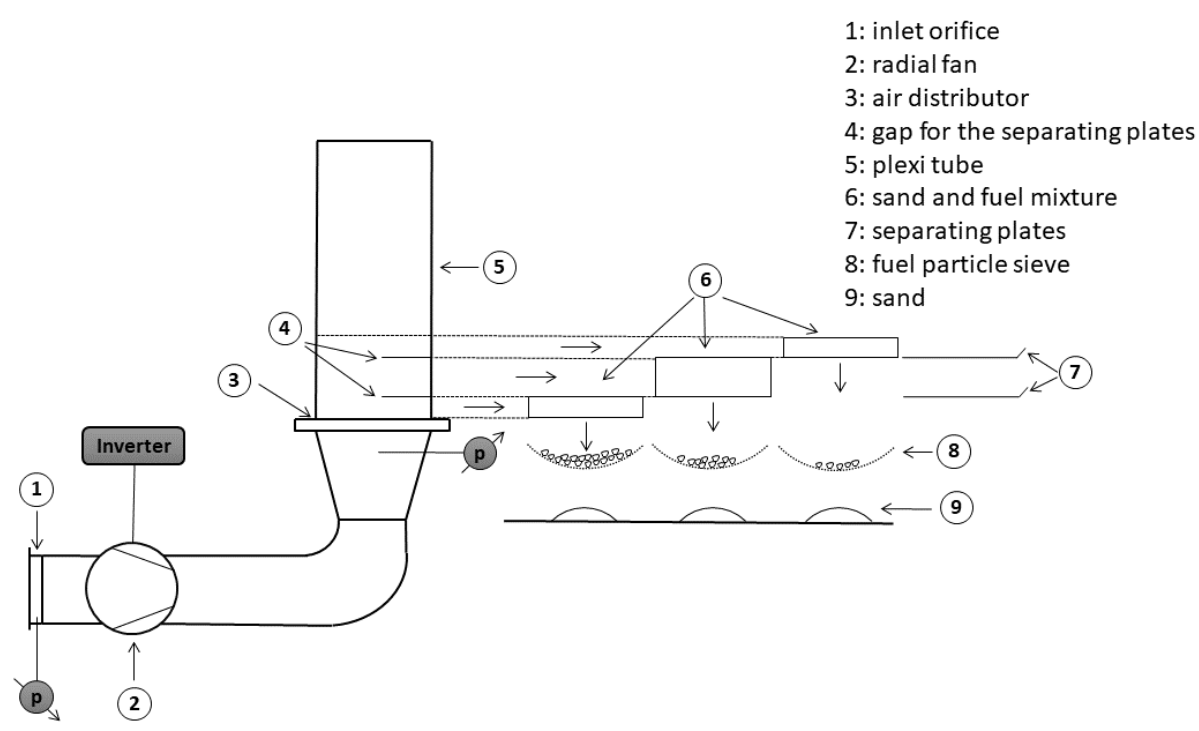

Figure 4. Schematic of the measuring setup and method of the particle mixing investigations.

The measurement method consists of the following steps:

- Filling the plexi tube with a mixture of about $50 \mathrm{~g}$ fuel and $1500 \mathrm{~g}$ sand. 
- Fluidizing the mixture with air of a velocity of 1.2 times the minimum fluidization velocity of the sand till the steady state is achieved (2-20 min).

- Sudden closing of the fluidization air.

- Slicing the bed into three vertical partitions with copper separators, at heights of 2 and $8 \mathrm{~cm}$.

- Evacuating the sliced partitions using a vacuum pump.

- Measuring the fuel mass after sieving.

- Repeating the measurement at other fluidization velocities, at 1.4, 1.6, 1.8, and 2.0 times the minimum fluidization velocity of the sand.

- Plotting the measured fuel mass fraction with the dimensionless fluidization velocity.

\section{Results and Discussion}

\subsection{Particle Size Distribution}

Figure 5 shows the measured particle size distribution (PSD) data of all investigated biomass fuels, together with the best fitting Rosin-Rammler distribution curves. Table 4 presents the Rosin-Rammler fitting parameters for each material, that is, a detailed summary of the resulted parameters on the geometrical properties of the investigated renewable fuels.

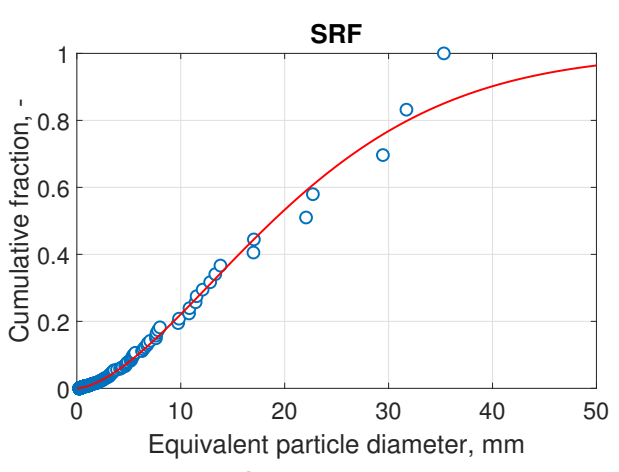

Sunflower shell

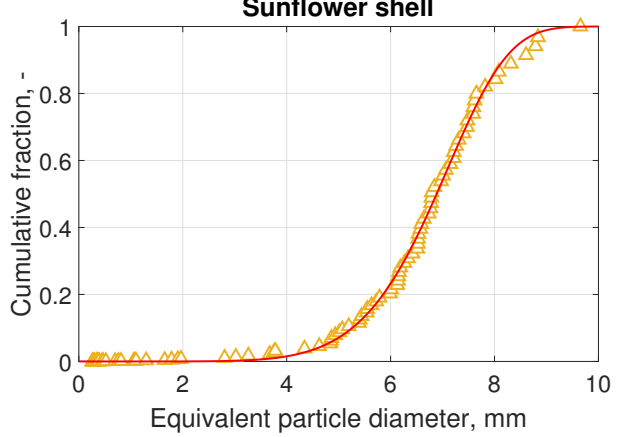

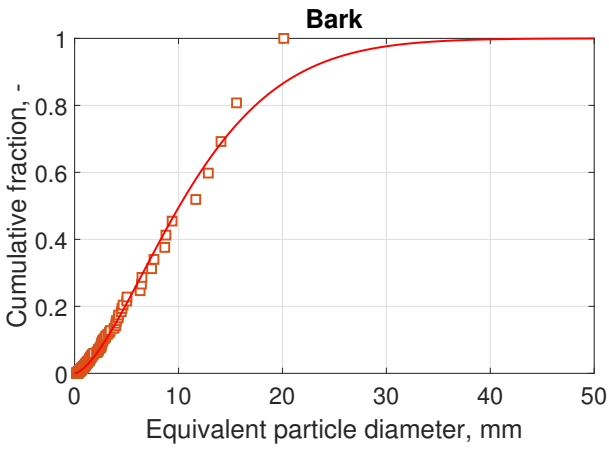

Wheat shell

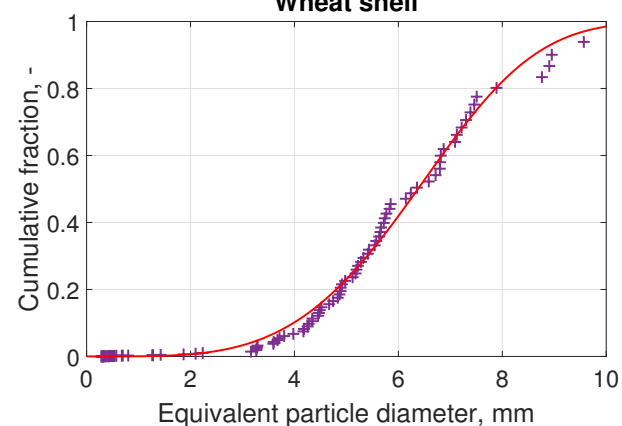

Figure 5. Particle size distribution of solid refused fuel (SRF), bark, sunflower shell, and wheat shell (markers), and the best-fitting Rosin-Rammler curves (solid lines).

Table 4. Parameters of the Rosin-Rammler distribution corresponding to the best fit with the measured data.

\begin{tabular}{lccc}
\hline \multicolumn{4}{c}{$\begin{array}{c}\text { Cumulative Fraction, } \boldsymbol{Y}_{\mathrm{i}}=\mathbf{1}-\exp \left[-\left(\boldsymbol{d}_{\mathrm{i}} / \boldsymbol{d}_{\mathrm{m}}\right)^{\mathrm{n}}\right] \\
\boldsymbol{d}_{\mathrm{i}} \text { : Equivalent Particle Diameter, } \mathbf{m m}\end{array}$} \\
\hline & $\begin{array}{c}\text { Mean Diameter } \\
\boldsymbol{d}_{\mathbf{m}}, \mathbf{m m}\end{array}$ & $\begin{array}{c}\text { Spread Parameter } \\
\boldsymbol{n},-\end{array}$ & $\begin{array}{c}\text { Regression } \\
\boldsymbol{R}^{\mathbf{2}}, \boldsymbol{\%}\end{array}$ \\
\hline SRF & 23.69 & 1.61 & 98.98 \\
Bark & 13.30 & 1.55 & 98.96 \\
Sunflower shell & 7.26 & 7.00 & 99.75 \\
Wheat shell & 6.99 & 4.00 & 99.30 \\
\hline
\end{tabular}




\subsection{Particle Entrainment}

Particle entrainment is one of the fluid-dynamic characteristics that depend on the type of the actual solid fuel. Figure 6 presents the accumulated entrained mass fraction of the investigated particles (SRF, bark, sunflower shell, and wheat shell) as function of the superficial gas velocity. This figure shows that there is a significant difference in the entrainment behaviors of the investigated particles. For example, the sunflower shells entrain from the bed in the highest degree; however, at very low velocity, the entrainment of wheat shell is the most intensive. The entrainment behaviors of the investigated SRF and bark samples are similar. However, the SRF is entrained relatively less than the bark at the low fluidization velocities, and more than the bark at elevated velocities. Also, the $50 \%$-entrainment line shows that the velocity at which $50 \%$ of the investigated particles is entrained is higher for the larger particles (SRF and bark), irrespectively of their diverse densities.

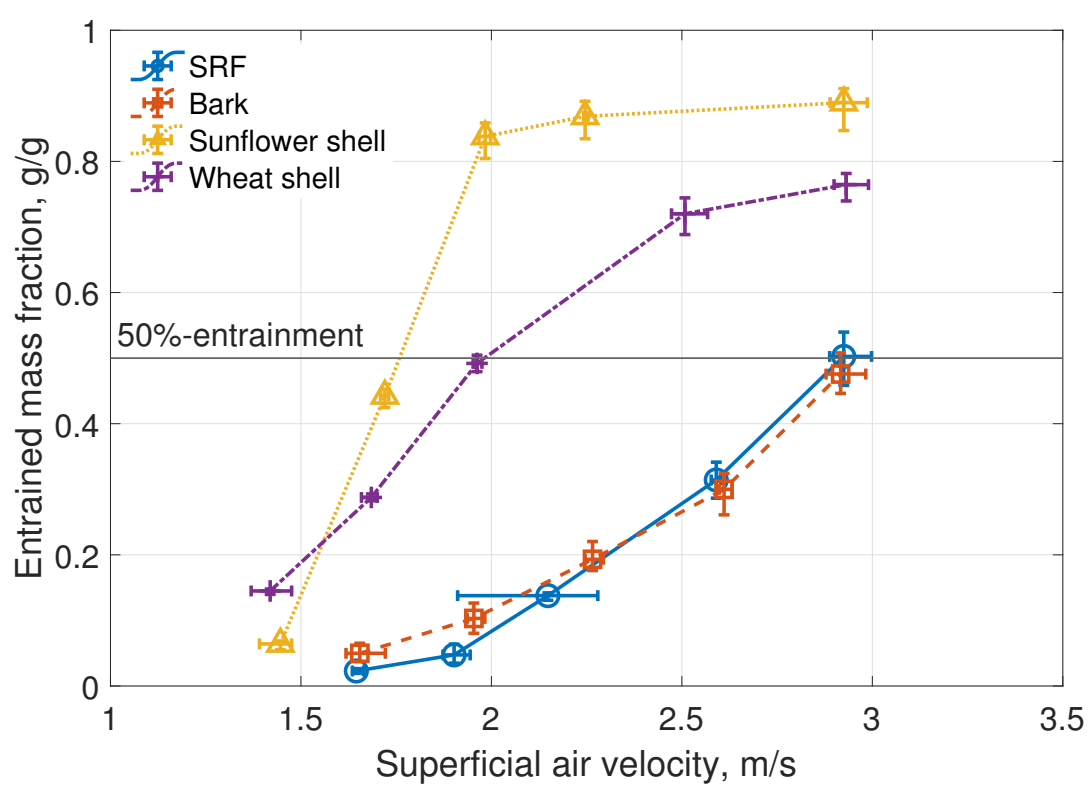

Figure 6. Particle entrainment as function of the superficial air velocity of SRF, bark, sunflower shell, and wheat shell. (Error bars on the above figure represent the repeatability error, while the precision error of the measuring instruments are $\pm 0.05 \mathrm{~g}$ for weight, and $\pm 0.009 \mathrm{~m} / \mathrm{s}$ for velocity)

Haider and Levenspiel [29] proposed an empirical-based chart for estimating the particle terminal velocity. This chart contains a set of curves offsetting by the degree of particle sphericity. Figure 7 show this chart, together with the data representing the renewable fuels as measured in the current work. The $50 \%$ entrainment data were taken from Figure 6 as they characterize well the sets of irregular particles. Figure 7 indicates that the investigated renewable fuels behave like low sphericity particles. More precisely, the curve running closest to the data gained from the SRF measurements corresponds to a sphericity of $\phi_{\mathrm{SRF}}=0.123$, and similar conclusions can be taken for all other investigated fuels. According to this, the characteristic sphericity of bark and wheat shell is $\phi_{\text {Bark }}=\phi_{\mathrm{W} \text {.Shell }}=0.043$, and that of sunflower shell can be well approximated by $\phi_{\mathrm{S} \text {.Shell }}=0.035$.

In fluidized bed energy applications, the operating temperature is high and it depends on the conversion process e.g., incineration, gasification, pyrolysis, and carbonization. The present measurements were performed on a cold basis to avoid conversion of the active particles. Furthermore, we need to address exclusively the fluid dynamic phenomenon without complications that can result from the hot-condition. To over come this technical problem, we need to link the superficial velocity of the hot basis to the investigated cold basis superficial velocity range. This correction can be obtained from the similarity of the drag force between the hot basis and the cold basis. Therefore, the consequent 
similarity of the particle Reynolds number $\left(\operatorname{Re}=\rho_{g} u_{g} d_{p} / \mu_{g}\right)$ is used to obtain the hot basis superficial velocity as follows:

$$
\begin{aligned}
& \left.\operatorname{Re}^{\prime}\right|_{T^{\circ} \mathrm{C}}=\left.\operatorname{Re}\right|_{25{ }^{\circ} \mathrm{C}} \\
& \left.\frac{\rho_{g}^{\prime} u_{g}^{\prime} d_{p}}{\mu_{g}^{\prime}}\right|_{T^{\circ} \mathrm{C}}=\left.\frac{\rho_{g} u_{g} d_{p}}{\mu_{g}}\right|_{25^{\circ} \mathrm{C}}
\end{aligned}
$$

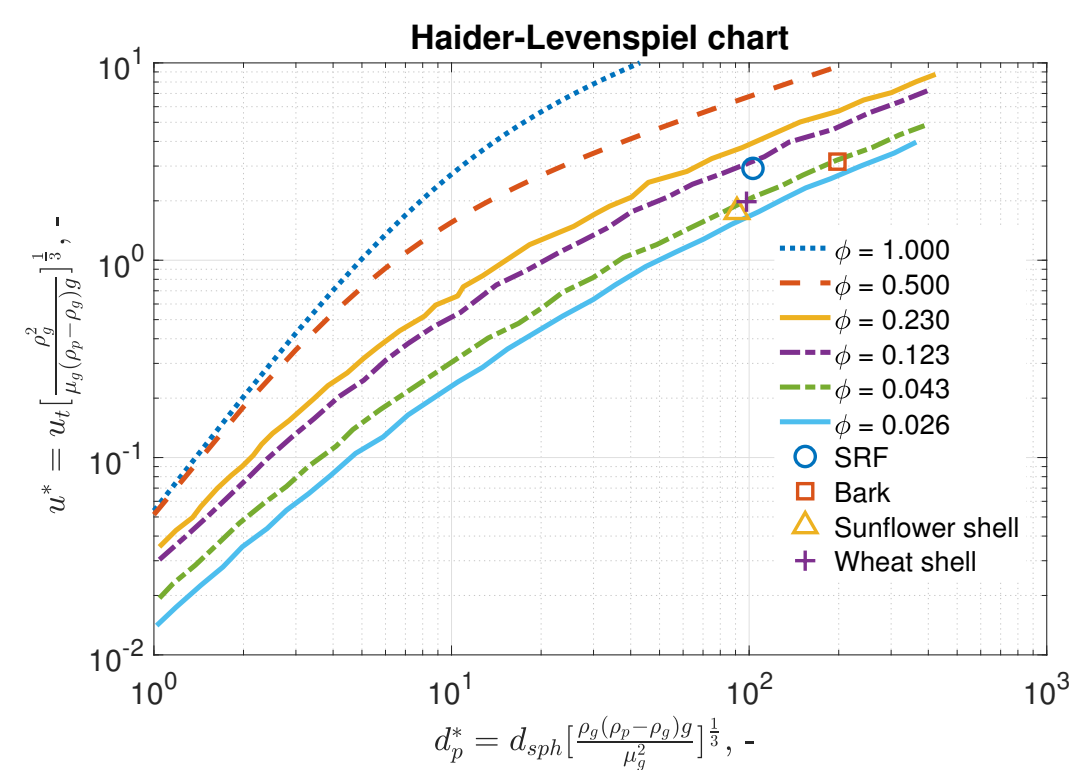

Figure 7. The Haider and Levenspiel [29] terminal velocity curves and the mean points (@ 50\% entrainment) of the investigated renewable fuels for determining their characteristic sphericity values.

Figure 8 shows the correction of the superficial velocity related to different operating temperatures. By this way, we can calculate the particles entrainment in hot basis, indirectly by first estimating the Re-equivalent cold superficial velocity from Figure 8 . The, substitution with the superficial air velocity in Figure 6 to get the accumulated entrained mass fraction. For example, the incineration hot basis superficial velocity of $0.2 \mathrm{~m} / \mathrm{s}$ can entrain the wheat shell at a rate of $73 \%$.

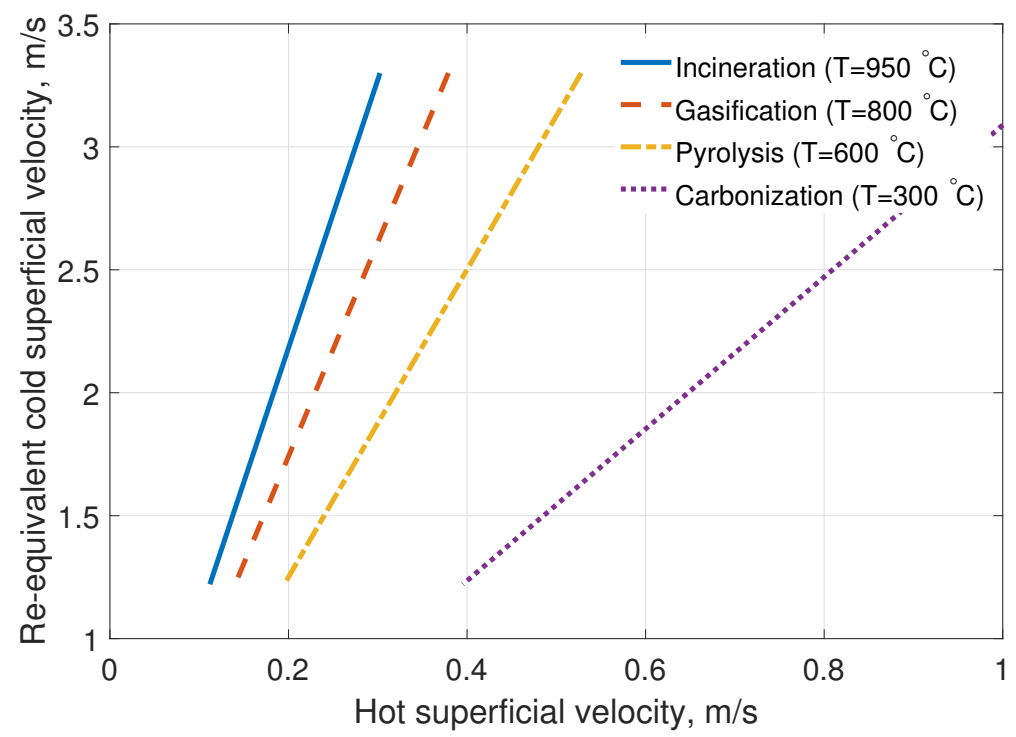

Figure 8. Superficial velocity correction related to the operating temperature. 


\subsection{Mixing in Binary-Mixture Fluidized Beds}

The mixing of the active particles with the bed material has a significant effect on many other phenomena like spatial temperature distribution and emissions-control reactions. Because of this, the main question to be answered by the evaluated experiments of this part of the study was, whether where the renewable fuels are placed within the reactor. The goal of each fluidized bed reactor is, of course, to keep the active particles inside the bed, that is, vertically, in the central region of the bed, which is also called the bed body [16,30]. For discussing this, the relative mass fraction is the most appropriate measure, as it is defined as the mass ratio of the active particles within the selected region over the amount of active particles in the whole bed. In this study, the following regions were considered, the top, center, and bottom of the bed. This corresponds to the industrial need for keeping the active particles within the bed body because the particles floating above the bed or sinking to the bottom do practically not utilize the advantages of the fuidized bed itself [16].

Regarding another measure, the mass ratio of the active particles over the bed material, the industrially relevant scale was considered as it was kept between 1.96 to $3.2 \%$.

Figure 9 shows the vertical arrangement of the investigated renewable active particles as functions of the fluidization velocity. As visible, SRF has relatively high mass fraction in the central region (in the bed body) and at the bottom of the fluidized bed at low superficial velocities, while at elevated velocities, the entire mass of this fuel is shifted upwards. The opposite tendency can be observed in cases of all other investigated biomass fuels.
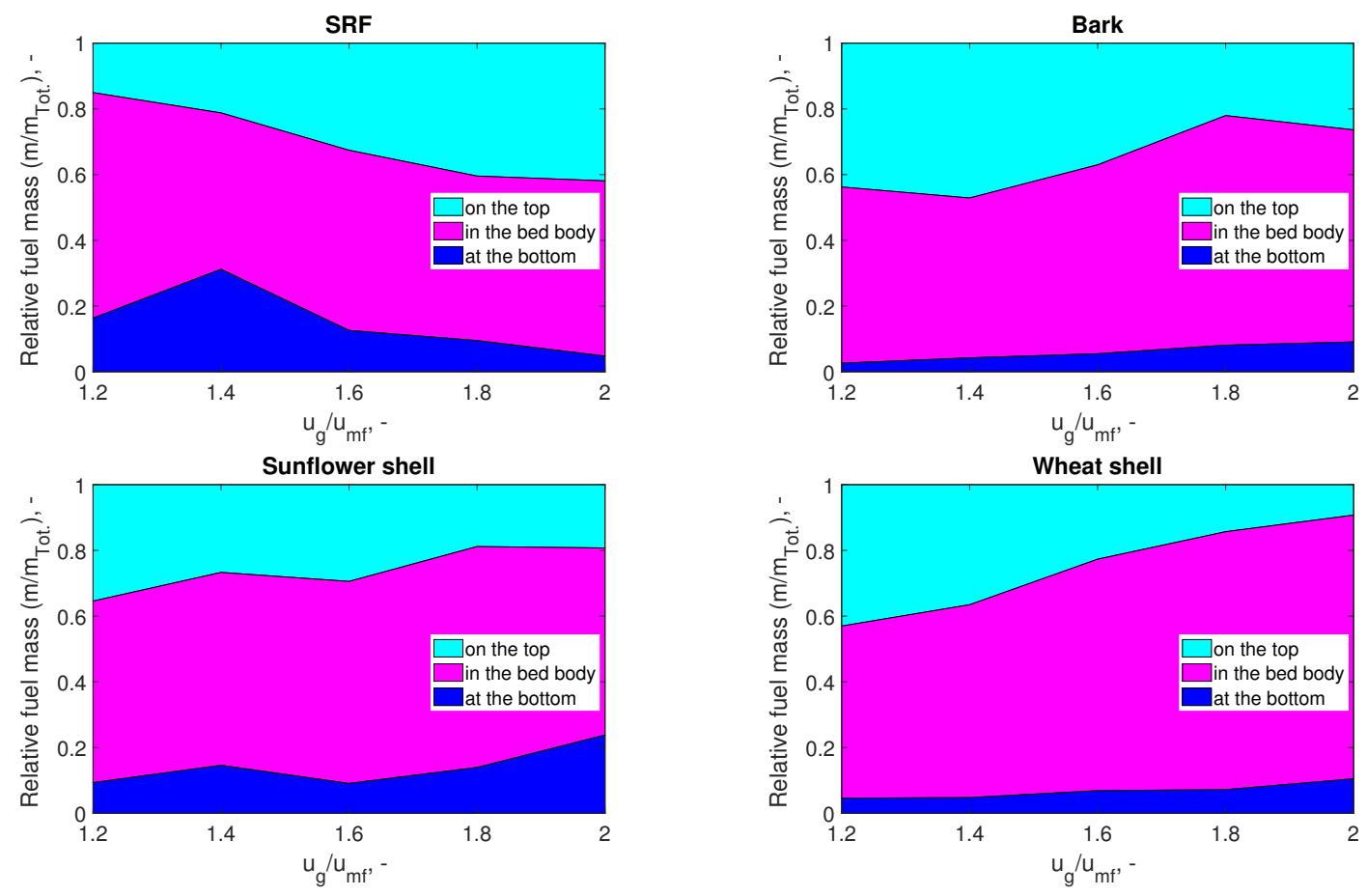

Figure 9. Vertical distributions (relative mass fractions) of the investigated biomass fuels in binary-mixture beds at different fluidization velocities.

This dissimilar mixing behavior of the SRF can be attributed to its non-homogeneous composition (due to diverse materials) compared to the other investigated active particles. Another possible reason is the particle size, e.g., the SRF has the widest PSD and the biggest mean size (see Figure 5). When the fluidization velocity increases, the number and size of gas bubbles increase, and this causes the shifting of the big SRF particles upwards (the umbrella effect).

It is to note that no correlation was observed between the mixing characteristics and the entrainment behavior of the investigated biomass fuels. 
On the other hand, it is also important to understand the difference in the mixing characteristic among these nonspherical active particles and a representative spherical tracer. Previously, Wirsum [31] studied the segregation behavior of the active particles in a fluidized bed using a spherical tracer in electromagnetic field [32]. The spherical tracer had an average density of $720 \mathrm{~kg} / \mathrm{m}^{3}$ and a diameter of $60 \mathrm{~mm}$. This tracer showed clear segregation with an inverted-C profile when fluidized in sand. Figure 10 presents a comparison among the vertical concentration of the SRF, bark, sunflower shell, wheat shell, and the spherical tracer of Wirsum [31] in the bubbling fluidized bed. (Note that the vertical concentration used here differs from the mass fraction used in Figure 9 because the concentration depends on the mass of the bed material and the volume.)

Figure 10 shows relatively higher concentration of the nonspherical active particles in the bottom region of the bed, which is in good agreement with the literature data $[28,33,34]$. This comparison indicates that the nonspherical active particles tend to exist in the bottom region more than the spherical tracer, as indicated by its lower concentration (probability) values. While the spherical tracer has a higher concentration in an upper region of the bed in comparison with the nonspherical active particles (SRF, bark, sunflower shell, and wheat shell). This finding recommends that the results obtained from spherical tracers should not be considered as an appropriate representation of the mixing characteristics of nonspherical, heterogeneous active particles.

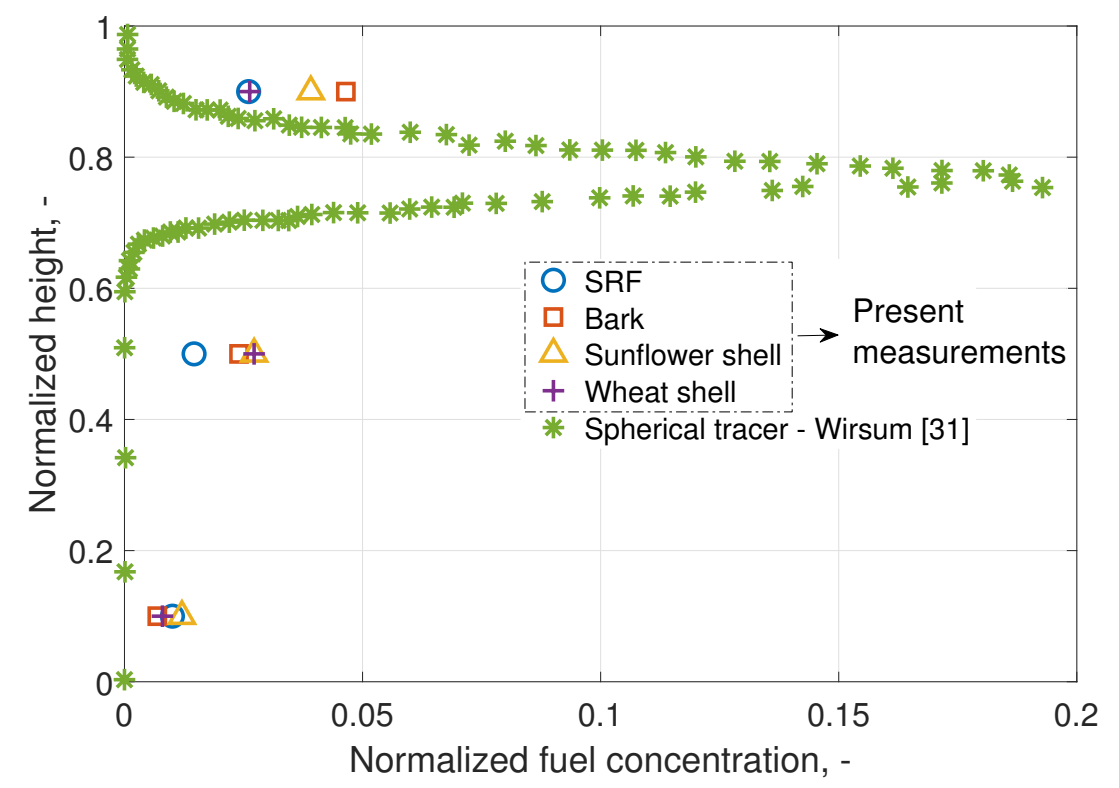

Figure 10. Comparison among the vertical concentrations of the investigated active particles and the spherical tracer [31] in the bubbling fluidized bed. $\left(u_{\mathrm{g}} / u_{\mathrm{mf}}=1.6\right.$ "present measurements", $u_{\mathrm{g}} / u_{\mathrm{mf}}=1.52$ "Wirsum [31]". The percentage errors of the present concentration results are $\pm 12.5 \%$ at the bottom, $\pm 8.3 \%$ in the bed body, and $\pm 50 \%$ on the top region.)

\section{Conclusions}

In this study, particle entrainment and mixing of industrially relevant fuels such as solid refused fuel/refuse derived fuel (SRF/RDF), bark, sunflower shell, and wheat shell were investigated. A lab-scale fluidized bed experimental facility was used for the measurements. The superficial velocity range was $1-3 \mathrm{~m} / \mathrm{s}$ in the entrainment measurements, while in the mixing measurements, it was 1.2-2.0 times the minimum fluidization velocity. In the mixing measurements, the mass ratio of the active particles was within the industrial relevance range (1.96-3.2\%). The findings obtained from this study can be summarized as follows: 


\section{Entrainment:}

- The sunflower shell entrained at the highest degree.

- At very low velocity, the entrainment of the wheat shells is the most intensive.

- SRF and bark has similar entrainment behavior, but with a less steep gradient.

Mixing:

- SRF has relatively high mass fraction in the bottom and center regions of the fluidized bed at low superficial velocities.

- Unlike all the biomass fuels, SRF tends to shift upwards at elevated velocities.

- The nonspherical active particles have higher concentrations at the bottom region than spherical ones.

Finally, we can conclude that the sunflower shell and wheat shell are not suitable for fluidized bed combustion because they entrain from the bed rapidly.

Author Contributions: All the authors of the present research contributed equally to conducting and writing this paper. All authors have read and agreed to the published version of the manuscript.

Funding: The research reported in this paper has been supported by the National Research, Development, and Innovation Fund (TUDFO/51757/2019-ITM, Thematic Excellence Program and the National Research, Development, Innovation Fund of Hungary in the frame of FIEK_16-1-2016-0007 (Higher Education and Industrial Cooperation Center), and the ÚNKP-19-3-I-BME-270 New National Excellence Program of the Ministry for Innovation and Technology.

Acknowledgments: The authors thank Laszlo Krisztina for permitting the use of her lab instruments for the present density experiments. We also extend our thanks to her lab member Bosznai Gyorgy for his support.

Conflicts of Interest: The authors declare no conflict of interest.

\section{References}

1. Yang, W.C. (Ed.) Handbook of Fluidization and Fluid-Particle Systems; Number 91 in Chemical Industries; OCLC: ocm52260128; Marcel Dekker: New York, NY, USA, 2003.

2. ECN-Netherlands. RDF (ID-Number: 849). Available online: https://phyllis.nl/Biomass/View/84 (accessed on 27 April 2020).

3. ECN-Netherlands. Bark (ID-Number: 51). Available online: https://phyllis.nl/Biomass/View/51 (accessed on 27 April 2020).

4. Demirbaş, A. Fuel Characteristics of Olive Husk and Walnut, Hazelnut, Sunflower, and Almond Shells. Energy Sources 2002, 24, 215-221. [CrossRef]

5. Fryda, L. Wheat Straw (ID-Number: 3563). Available online: https://phyllis.nl/Biomass/View/356 (accessed on 27 April 2020).

6. ECN-Netherlands. Coal, Lignite (ID-Number: 2847). Available online: https://phyllis.nl/Biomass/View / 2847 (accessed on 27 April 2020).

7. Estejab, B.; Battaglia, F. Modeling of Coal-Biomass Fluidization Using Computational Fluid Dynamics. In Volume 7A: Fluids Engineering Systems and Technologies; American Society of Mechanical Engineers: San Diego, CA, USA, 2013; p. V07AT08A058. [CrossRef]

8. Mätzing, H.; Gehrmann, H.J.; Seifert, H.; Stapf, D. Modelling grate combustion of biomass and low rank fuels with CFD application. Waste Manag. 2018, 78, 686-697. [CrossRef]

9. Haaf, M.; Peters, J.; Hilz, J.; Unger, A.; Ströhle, J.; Epple, B. Combustion of Solid Recovered Fuels within the Calcium Looping Process-Experimental Demonstration at 1 MWth Scale. Exp. Therm. Fluid Sci. 2019, 113, 11002. [CrossRef]

10. Vonk, G.; Piriou, B.; Felipe Dos Santos, P.; Wolbert, D.; Vaïtilingom, G. Comparative analysis of wood and solid recovered fuels gasification in a downdraft fixed bed reactor. Waste Manag. 2019, 85, 106-120. [CrossRef] [PubMed]

11. Valin, S.; Ravel, S.; Pons de Vincent, P.; Thiery, S.; Miller, H. Fluidized bed air gasification of solid recovered fuel and woody biomass: Influence of experimental conditions on product gas and pollutant release. Fuel 2019, 242, 664-672. [CrossRef] 
12. De Gisi, S.; Chiarelli, A.; Tagliente, L.; Notarnicola, M. Energy, environmental and operation aspects of a SRF-fired fluidized bed waste-to-energy plant. Waste Manag. 2017, 73, 271-286. [CrossRef]

13. Hervy, M.; Remy, D.; Dufour, A.; Mauviel, G. Air-blown gasification of Solid Recovered Fuels (SRFs) in lab-scale bubbling fluidized-bed: Influence of the operating conditions and of the SRF composition. Energy Convers. Manag. 2019, 181, 584-592. [CrossRef]

14. Morris, J.D.; Daood, S.S.; Chilton, S.; Nimmo, W. Mechanisms and mitigation of agglomeration during fluidized bed combustion of biomass: A review. Fuel 2018, 230, 452-473. [CrossRef]

15. Behainne, J.J.R.; Martinez, J.D. Performance analysis of an air-blown pilot fluidized bed gasifier for rice husk. Energy Sustain. Dev. 2014, 18, 75-82. [CrossRef]

16. Szentannai, P.; Szücs, B. Vertical arrangement of SRF particles in a stationary fluidized bed. Powder Technol. 2018, 325, 209-217. [CrossRef]

17. Zhou, T.; Yang, S.; Wei, Y.; Hu, J.; Wang, H. Impact of wide particle size distribution on the gasification performance of biomass in a bubbling fluidized bed gasifier. Renew. Energy 2019, 148, 534-547. [CrossRef]

18. Yang, S.; Zhou, T.; Wei, Y.; Hu, J.; Wang, H. Influence of size-induced segregation on the biomass gasification in bubbling fluidized bed with continuous lognormal particle size distribution. Energy Convers. Manag. 2019, 198, 111848. [CrossRef]

19. Kraft, S.; Kirnbauer, F.; Hofbauer, H. Investigations using a cold flow model of char mixing in the gasification reactor of a dual fluidized bed gasification plant. Powder Technol. 2017, 316, 687-696. [CrossRef]

20. Köhler, A.; Rasch, A.; Pallarès, D.; Johnsson, F. Experimental characterization of axial fuel mixing in fluidized beds by magnetic particle tracking. Powder Technol. 2017, 316, 492-499. [CrossRef]

21. Win, K.K.; Nowak, W.; Matsuda, H.; Hasatani, M.; Bis, Z.; Krzywanski, J.; Gajewski, W. Transport Velocity of Coarse Particles in Multi-Solid Fluidized Bed. J. Chem. Eng. Jpn. 1995, 28, 535-540. [CrossRef]

22. Liang, Z.; Nie, Z.; An, A.; Gong, J.; Wang, X. A particle shape extraction and evaluation method using a deep convolutional neural network and digital image processing. Powder Technol. 2019, 353, 156-170. [CrossRef]

23. Wu, L.C.; Yu, C. Powder Particle Size Measurement with Digital Image Processing Using Matlab. Adv. Mater. Res. 2012, 443-444, 589-593. [CrossRef]

24. Lu, Z.; Hu, X.; Lu, Y. Particle Morphology Analysis of Biomass Material Based on Improved Image Processing Method. Int. J. Anal. Chem. 2017, 2017, 5840690. [CrossRef]

25. Huilin, L.; Yurong, H.; Gidaspow, D.; Lidan, Y.; Yukun, Q. Size segregation of binary mixture of solids in bubbling fluidized beds. Powder Technol. 2003, 134, 86-97. [CrossRef]

26. Wu, S.; Baeyens, J. Segregation by size difference in gas fluidized beds. Powder Technol. 1998, 98, 139-150. [CrossRef]

27. Olivieri, G.; Marzocchella, A.; Salatino, P. Segregation of fluidized binary mixtures of granular solids. AIChE J. 2004, 50, 3095-3106. [CrossRef]

28. Zhang, Y.; Jin, B.; Zhong, W. Experimental investigation on mixing and segregation behavior of biomass particle in fluidized bed. Chem. Eng. Process. Process. Intensif. 2009, 48, 745-754. [CrossRef]

29. Haider, A.; Levenspiel, O. Drag coefficient and terminal velocity of spherical and nonspherical particles. Powder Technol. 1989, 58, 63-70. [CrossRef]

30. Botond Szücs.; Pál Szentannai. Experimental Investigation on Mixing and Segregation Behavior of Oxygen Carrier and Biomass Particle in Fluidized Bed. Period. Polytech. Mech. Eng. 2019, 63, 188-194. [CrossRef]

31. Wirsum, M.; Fett, F.; Bausch, T.; Lütge, C. Über die Eignung von Feuerungsanlagen mit Wirbelschicht zur Verbrennung von kommunalem Klärschlamm. VDI Berichte 1996, 1280, $209-224$.

32. Wirsum, M.; Fett, F.; Iwanowa, N.; Lukjanow, G. Particle mixing in bubbling fluidized beds of binary particle systems. Powder Technol. 2001, 120, 63-69. [CrossRef]

33. Fotovat, F.; Chaouki, J.; Bergthorson, J. Distribution of large biomass particles in a sand-biomass fluidized bed: Experiments and modeling. AIChE J. 2014, 60, 869-880. [CrossRef]

34. Cluet, B.; Mauviel, G.; Rogaume, Y.; Authier, O.; Delebarre, A. Segregation of wood particles in a bubbling fluidized bed. Fuel Process. Technol. 2015, 133, 80-88. [CrossRef]

(C) 2020 by the authors. Licensee MDPI, Basel, Switzerland. This article is an open access article distributed under the terms and conditions of the Creative Commons Attribution (CC BY) license (http://creativecommons.org/licenses/by/4.0/). 